\title{
HOW EFFICIENT ARE REAL ESTATE AND CONSTRUCTION COMPANIES IN IRAN'S CLOSE ECONOMY?
}

\author{
Wai Peng WONG ${ }^{1}$, Hassan Fereidouni GHOLIPOUR ${ }^{2}$ and Ebrahim BAZRAFSHAN ${ }^{3}$ \\ ${ }^{1}$ School of Management, Universiti Sains Malaysia (USM), 11800 Penang, Malaysia \\ E-mail: wongwp@usm.my \\ ${ }^{2}$ School of Management, Universiti Sains Malaysia (USM), 11800 Penang, Malaysia \\ E-mail: hassanhgf@gmail.com \\ ${ }^{3}$ School of Management, Universiti Sains Malaysia (USM), 11800 Penang, Malaysia \\ E-mail: bazrafshan.e1983@gmail.com
}

Received 11 October 2011; accepted 16 April 2012

\begin{abstract}
This paper empirically explores various efficiency aspects of real estate and construction companies in Iran in light of their remarkable growth in recent years. The technique used to measure the efficiency is DEA and the sample is taken from the construction and real estate companies in Iran. Results from our analysis reveal that most of the real estate and construction companies in Iran are generally technical, scale and mix efficient. However, they are less cost efficient due to increasing higher cost of production. The sensitivity analysis results also suggest that the real estate and construction companies are experiencing diseconomies of scale. As Iran is an underdeveloped market and is currently one of the most interesting frontier markets in the world, this research contributes substantially to investors and multinationals (who have growing desire to gain exposure in this market) by providing current information about the efficiencies of real estate and construction companies in Iran. In addition, this research also provides some institutional voids on how to penetrate market environment in Iran through real estate development.
\end{abstract}

KEYWORDS: Listed real estate and construction companies; DEA; Efficiency; Iran

\section{INTRODUCTION}

Real estate and construction industry is an important pillar of Iran's economy. A recent statistics provided by GMID (2011) indicates that real estate and construction sector contributed about 17 percent of Iranian Gross Domestic Product (GDP) over the period of 1995-2009. Moreover, private sector investment in buildings in urban areas increased from 7,555.4 billion Rials ${ }^{1}$ in 1995 to $313,728.6$

1 Iranian currency is the Rial. Exchange rate is around US\$1 = Rials 12000 as of February 2012. billion Rials in 2008. The large development of this sector is profoundly due to urbanization and population growth which have created high demand for land and residential properties $^{2}$.

The development in the Iranian property market has drawn the attention of most stock market investors to the property securities. As a result, the property price index increased and the property stock holders benefited over the period of 2008-2010 (see Figure 1).

\footnotetext{
2 Consumer expenditure on housing is by far the highest compared to other categories of household expenditures, taking a 30\% share (GMID, 2011).
}

Copyright (C) 2012 Vilnius Gediminas Technical University (VGTU) Press Technika http://www.tandfonline.com/TSPM 
Given the importance of this sector for portfolio investors in Iran, there are two fundamental questions for them to be answered. (1) How do listed real estate and construction companies perform in terms of technical efficiency and cost efficiency? (2) Can a company be both cost and technical efficient? These two questions are important as they provide insights to foreign investors who want to tap into the underdeveloped market of Iran which has huge potential. To answer these questions we apply Data Envelopment Analysis (DEA) which is a non-parametric technique to estimate the efficiency of the Iranian listed real estate and construction companies. DEA has the advantage of not requiring assumptions about functional form or the properties of a random error term; rather efficiency is measured for each firm by constructing dominating or reference sets of efficient firms in the industry.

Our paper contributes to the literature and provides some implications for portfolio investors and companies' managers. Firstly, most studies in this area cover United States, Western Europe, Hong Kong and China real estate markets. Since findings for these countries might not be directly transferable to a Middle Eastern country such as Iran, therefore, more work is necessary to obtain a clearer picture of real estate and construction companies' performance in the Middle East region. In fact, our findings provide an insight into a market which is under-researched. Secondly, while the DEA application to real estate efficiency context may not be new, past researches had primarily focused within the internal operational analysis; in contrast, our study had discriminated against various efficiency sources which further connote the overall cost competitiveness of the organizations. Thirdly, our findings provide some implications for Iranian and potential foreign investors to make necessary investment decisions. Finally, the results would be beneficial for top managers of listed real estate and construction companies to adopt appropriate policies to enhance their efficiency. This will help to sustain the real estate and investment market in the long run.

The rest of the paper is organized as follows. Section 2 reviews relevant literature. Section 3 explains the DEA technique, data and data sources. Section 4 presents empirical analysis. Section 5 discusses the obtained results. Section 6 presents the sensitivity analysis and managerial implications and finally Section 7 makes some concluding remarks.

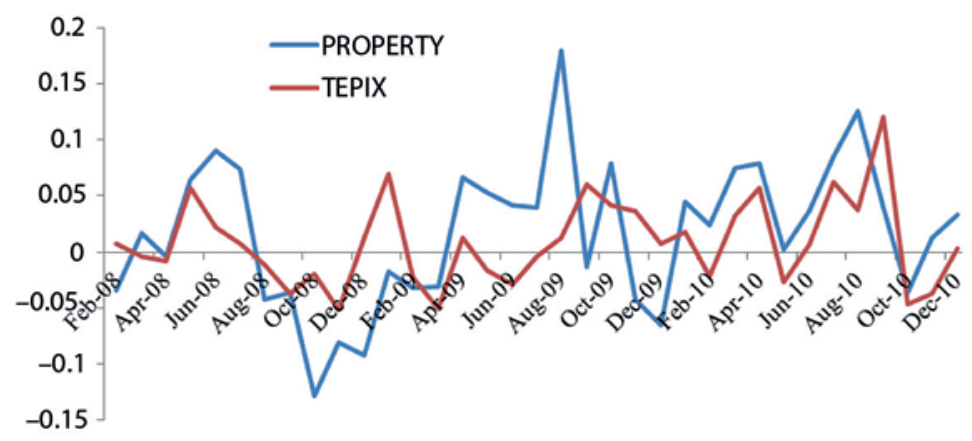

Figure 1. Return on Market Price Index (TEPIX) and return on Property Stock Price Index (PROPERTY) Source: Iran's Tehran Stock Exchange 


\section{LITERATURE REVIEW}

This section of paper intends to survey some of the previous researches which are relevant to our study. Using data for the years 1992-1996 and applying DEA, Anderson et al. (2002) measured technical efficiency and economies of scale for real estate investment trusts (REITs). They found that REITs are technically inefficient (a result of both poor input utilization and failure to operate at constant returns to scale). Moreover, their results suggested that many REITs could increase performance through expansion. Bers and Springer (1997) investigated economies of scale in U.S. REITs for the years 1992-1994. Their findings showed the existence of significant scale economies, suggesting that gains in productivity can be realized through expansion. By using panel data and applying DEA approach, Miller and Springer (2007) found no evidence of scale economies and some evidence of scale diseconomies for publicly traded REITs. Similarly, Miller et al. (2006) showed that the estimated returns to scale for publicly traded REITs do not support economies of scale. Zheng et al. (2011) employed three frontier-based DEA approaches to evaluate the operational efficiency of listed real estate companies in China's stock markets. Their results suggested that most of the inefficient companies could further increase their operating efficiency through scale expansion. In another study, Wang and Wang (2009) evaluated the operating performance of Chinese listed real estate companies. They found that efficiency of China's real estate industry is largely affected by the macroeconomic factors. By applying DEA approach, Topuz et al. (2005) empirically examined the U.S. REITs' operating efficiency. They found that REITs suffer substantial average inefficiency over the period (1989-1999). Furthermore, their results showed that most REITs experience significant scale inefficiencies. Using a translog cost function, Pan and Yang (2010) investigated scale economies for Chinese real estate industry over 2004-2008. Their analysis revealed that scale economies exist in Chinese real estate industry. Moreover, they found that the impact of scale economies is greater for smaller companies and non-state-owned ones. Hui et al. (2007) examined the performance of Hong Kong's property companies, and how well they do in comparison with Singapore property companies. Their findings pointed out that those Hong Kong's property companies that diversify their business investments could achieve relatively better economic performance in comparison with those focused solely in real estate. Furthermore, they found that property companies in Hong Kong achieved higher rate of returns on their capital invested than Singapore property companies. In their study on the investment performance of listed property and construction companies in Nigeria, Abdul-Rasheed and Tajudeen (2006) found that these companies do not perform better than stock market due to a declining profit margin. Moreover, their results showed that these companies offer diversification possibilities due to their low correlation with the stock market.

Wang and Chau (2001) applied DEA to evaluate technical efficiency in the construction industry of Hong Kong during 1981-1996. Their results showed an increasing trend in average technical efficiency. Moreover, they found that the higher technical efficiency ratios come from those construction firms with larger size, less intensive capital, a lower degree of subcontracting, and a lower proportion of intermediate input consumption. You and Zi (2007) analyzed three different types of efficiency for the Korean construction industry for the period 1996 to 2000. By utilizing the DEA method, their results show that efficiency measures decreased significantly during the period 1996 to 2000 and that there were large differences over the period before and after the 1997 economic crisis. Furthermore, they found that the low level of cost efficiency of the 
Korean construction industry was largely due to allocative inefficiency. Horta et al. (2011) evaluated the financial performance and competitive environment of the construction industry in Portugal between 1996 and 2007. Using DEA and complemented with bootstrapping, they found that the performance of Portuguese construction companies increased during the period of study. Moreover, their results showed that large companies and small specialized companies could achieve the best performance levels. Their results of the assessment also suggested that the innovators are companies with high profitability. Tsolas (2011) evaluated the profitability and effectiveness of 16 Greek-listed construction firms. By using a new framework that integrates DEA and ratio analysis, he showed that there is a positive link between profitability efficiency and effectiveness. Moreover, his results pointed out both efficiency and effectiveness drivers are related to the operational space of the construction firms. Based on the field data collected from 74 construction firms, El-Mashaleh et al. (2007) proposed benchmarking models to analyze and critique both the performance measures and metrics used traditionally in the construction industry and the benchmarking models that had been developed for the industry. Their findings suggested some implications how resources should be reallocated to improve overall construction companies' performance. Similarly, Yang et al. (2010) summarized the recent performance measurement research studies in construction and provided a comprehensive performance measurement model for the construction industry.

It is apparent from the literature that although numerous studies have attempted to assess real estate and construction companies' efficiency in the West and China, to our knowledge, none of the previous studies has focused on assessing efficiency of Iranian real estate and construction companies. Therefore, this research aims to address this shortcoming.

\section{TECHNIQUE AND DATA}

\subsection{DEA}

Data Envelopment Analysis (DEA) is a mathematical programming technique that calculates the relative efficiencies of multiple decision-making units (DMUs) and is suitable to be used in measuring real estate efficiency because it can handle multiple inputs and outputs. Further, it does not require prior unrealistic assumptions on the variables, and explores and identifies the underlying causes of the inefficiencies. DEA has been used successfully in evaluating the performance of many different types of entities in many different contexts e.g., in health care systems (Hollingsworth, 2008; Ozcan, 2008), banking (Cummins et al., 2010; Siriopoulos and Tziogkidis, 2010), public services (Odeck, 2008; Seol et al., 2008); and also other interesting applications such as Olympic Games (Wu et al., 2009) and macroeconomic policies (Shi et al., 2010).

The reasons of adopting DEA in our study are as follows. First, DEA has shown to perform well in empirical analyses. Cummins and Zi (1998) showed that DEA scores had high correlations with conventional performance measures compared to econometric models. Secondly, DEA also has the advantage of allowing for the relatively easy decomposition of cost efficiency into pure technical, scale and allocative efficiency as will be discussed in more details in following subsections.

DEA, being an extreme point technique where the efficiency frontier is formed by the actual performance of best performing companies, the efficiency scores are highly sensitive to small errors in measurement. When sample size is small, it would result in a large proportion of companies having an efficiency score of 1. In this paper, we will effectively circumvent this problem by introducing a virtual company, which at the same time also helps to do a full ranking of the DMUs in the efficiency dimensions. It is also important to highlight that 
before running the DEA models, data transformation has to be carried out as part of the requirement of using DEA technique. Later, section 3.1.1 will illustrate an example of data transformation.

To ease the understanding of the readers, we provide a section to explain the foundation of DEA technique.

\section{Foundations of DEA technique}

Efficiency measurement in DEA can be considered in terms of the optimal combination of inputs to achieve a given level of output (an input-orientation), or the optimal output that could be produced given a set of inputs (an output-orientation). DEA concept is based on the distance functions concept of measuring efficiency. Farrell (1957) introduced the concept of measuring efficiency based on distance functions $D(y, x)$ i.e., the distance of a given firm's output-input vector $(y, x)$ from the best practice production frontier. Intuitively, the firms that operate with the minimum amount of input needed to produce their quantity of output are deemed efficient, while those that are not, are the vice versa. Therefore, the operating points of fully efficient firms, $D(y, x)=1$, lie on the frontier; where else, inefficient firms lie outside of the frontier e.g., in the case judging efficient as using the minimum amount of input to produce the required output, the points will lie on the right of the frontier $D(y, x)>1$, indicating that they could reduce their input consumption while producing the same quantity of output.

This point suggests that the production function of the efficient firms must be known, but, in practice, this is not the case. From there on, Farrell (1957) suggested that the production frontier can be estimate via (a) a nonparametric piecewise-linear convex isoquant constructed to envelop all the points, or (b) a parametric function, such as the Cobb-Douglas form fitted to the data.

DEA is the non-parametric approach to frontier estimation, i.e., the type (a) method of constructing the frontier. DEA utilizes math- ematical programming, and is best presented in ratio form (Charnes et al., 1978). With reference to our research, the objective of the basic DEA model is to maximize the efficiency value of the real estate and construction companies under consideration via the selection of optimal weights associated with each input and output factor. For evaluating the efficiency value of a real estate company $j$, in consideration of $s$ outputs and $m$ inputs, the ratio model, given a reference set of $n$ companies is

$$
\begin{aligned}
\max _{\mathbf{v}_{\mathbf{o}} \mathbf{u}_{\mathbf{o}}} & \frac{\sum_{i=1}^{s} v_{i o} y_{i o}}{\sum_{j=1}^{m} u_{j o} x_{j o}}, \\
\text { s.t. } & \frac{\sum_{i=1}^{s} v_{i o} y_{i k}}{\sum_{j=1}^{m} u_{j o} x_{j k}} \leq 1, \quad \forall k \in\{1,2, \ldots, n\},
\end{aligned}
$$

where: $y_{i o}$ represents the level of output factor $i(\forall i \in\{1,2, \ldots, s\})$ and $x_{j o}$ represents the level of input factor $j(\forall j \in\{1,2, \ldots, m\})$. In addition, $v_{i o}$ represents the weight assigned for output factor $i$ and $u_{j o}$ represents the weight assigned for input factor $j . \mathbf{v}_{\mathbf{o}}$ and $\mathbf{u}_{\mathbf{o}}$ are $s$ and $m$ dimensional weight vectors representing the collection of $v_{i o}$ and $u_{j o}$ weights. Both of these vectors are non-negative.

The output of the model i.e., the efficiency value, enables firms to assess their relative efficiencies compared to other firms. The efficiency value provides insight into the relationship between how resources are expended and the relative success of outcomes. In addition, efficiency value allows for the measurement of the impact of certain technological and managerial factors on overall firm performance. In some cases, efficiency value is also able to determine the return on investment associated with specific firm action.

Next, various DEA models will be discussed; the intention of discussion is to explain the various DEA models and the corresponding efficiency scores as to what they represent in an organizational context. As such the math- 
ematical formulation and the technical portion will be brief, readers are advised to refer to Ali and Seiford (1993) and Charnes et al. (1978) for more details of the technique.

\subsubsection{Models forms and efficiency scores}

The efficiency models used in our assessment of real estate and construction companies include the technical efficiency and scale efficiency model, slack based efficiency and mix efficiency model, cost and allocation efficiency model.

\subsubsection{Technical efficiency and scale efficiency models}

Note that from the above nonlinear program, after linearized through a change in coefficients, the linearized dual form of the model is typically known as the CCR model (or envelopment model). This CCR model is typically presented in the DEA literature to assess the technical efficiency.

$$
\begin{aligned}
\min _{\theta_{C C R}, \lambda} & \theta_{C C R} \\
\text { s.t. } & \sum_{k=1}^{n} \lambda_{k} y_{i k}-y_{i o} \geq 0 \quad \forall i \in\{1,2, \ldots, s\}, \\
& \sum_{k=1}^{n} \lambda_{k} x_{j k}-\theta_{C C R} x_{j o} \leq 0 \quad \forall j \in\{1,2, \ldots, m\}, \\
& \lambda_{k} \geq 0 \quad \forall k \in\{1,2, \ldots, n\},
\end{aligned}
$$

where: $q_{C C R}$ is the dual variable to be minimized and $l$ is a vector in $K^{\mathrm{n}}$ comprising of the scalars $l_{k}(k \in\{1,2, \ldots, n\})$. From the organizational context, this CCR efficiency is equivalent to one minus the equi-proportional reduction in all input that still allows production of the same output. Thus, it follows that $0<q_{C C R} \leq 1$. Technical efficiency simply means how efficient are the firms in transforming their inputs (e.g., natural resources) into outputs (e. g., goods and services) without waste. It logically determines whether a firm or DMU (Note: in this paper, DMUs are the Iranian listed real estate and construction companies) can achieve the same or more out- put while requiring less input. If more output with less input can be achieved, the DMU/firm being evaluated is judged to be relatively inefficient; and vice versa.

\section{Example of data transformation}

In the presence of negative data in DEA evaluation, the values would need to be transformed by adding the smallest positive values $b$ that would make the data positive (i.e., greater than zero). For example, if the profit data $y_{i k}$ for three DMUs were $-1000,-50$, 300 and $b$ was set to 1010 . Hence, the transformed values $\hat{y}_{i k}=y_{i k}+\beta$ would be 10,960 and 1310. Note that the transformed values are sufficiently significant to represent positive profit values. Due to the translation invariance characteristic of DEA, values transformation will not affect the relative efficiencies of the DMUs. Transformation of data would require the modification of the envelopment model to enable a variable return to scale frontier. Therefore, a convexity constraint is added to (2), as shown in the model below, which is known as the VRS model. VRS model allows a variable return to scale in contrast to the CRS model which uses a constant return to scale, i.e, assuming that all firms will be operating at an optimal scale. The real environment which exerts imperfect competition, government regulations, and constraints on finance may not allow firm to operate at the optimal scale. Hence, VRS would be more appropriate in this context than the CRS model.

$$
\begin{aligned}
& \text { (TE) } \min _{\theta_{C C R}, \lambda} \theta_{V R S} \\
& \text { s.t. } \sum_{k=1}^{n} \lambda_{k} y_{i k}-y_{i o} \geq 0 \quad \forall i \in\{1,2, \ldots, s\}, \\
& \quad \sum_{k=1}^{n} \lambda_{k} x_{j k}-\theta_{V R S} x_{j o} \leq 0 \quad \forall j \in\{1,2, \ldots, m\} \\
& \lambda_{k} \geq 0 \quad \forall k \in\{1,2, \ldots, n\}, \\
& \quad \sum_{k=1}^{n} \lambda_{k}=1 .
\end{aligned}
$$


As the difference between (2) and (3) lies in the scale assumption (the prior is constant return to scale, while the later is variable return to scale), hence, the scale efficiency can be obtained through (4).

$$
(\mathrm{SE})=\theta_{C C R}^{*} / \theta_{V R S}^{*} \text {. }
$$

From the managerial context, the scale efficiency indicates to the firm how efficient it is with respect to the size of its operations. In other words, it addresses question i.e., is the firm in the "optimal size" to operate?

\subsubsection{Slack-based efficiency and mix efficiency model}

From (3), the decision maker will understand how efficient the firm in utilizing the input to produce an output. However, he/she may not know how efficient the inputs are being used collectively in producing the output. For example, given that the inputs are capital and number of employees, output is profit, the firm maybe technically efficient in maximizing the ratio of output over input; but in the process of achieving technical efficiency, there may be input excesses (e.g. some employees maybe idle), and output shortfalls (lower profit than target level). Hence, another type of DEA model i.e., the slack-based efficiency can be used to address this problem.

Technically, the slack based model (SBM) is in non-radial form, which has relaxed the assumption from the TE model that input-output proportions remain unchanged; in other words, it no longer assumes that proportionate increase (decrease) in any inputs will affect a similar proportionate amount of increase (decrease) in the outputs (Tone, 2001). This relaxation is valid because proportionality is not always true in actual practice. The SBM model is as follows

$$
\begin{aligned}
(\mathrm{SBM}) \min _{\mathbf{s}^{+}, \mathbf{s}^{-}, \lambda} & \theta_{S B M}=\frac{1}{\|M\|} \sum_{j=1}^{\|M\|} \frac{x_{j o}-s_{j}^{-}}{x_{j o}}, \\
\text { s.t. } & \sum_{k=1}^{n} \lambda_{k} y_{i k}-s_{i}^{+}=y_{i o} \quad \forall i \in\{1,2, \ldots, s\}, \\
& \sum_{k=1}^{n} \lambda_{k} x_{j k}+s_{j}^{-}=x_{j o} \quad \forall j \in\{1,2, \ldots, m\}, \\
& \sum_{k=1}^{n} \lambda_{k}=1, \\
& \lambda_{k} \geq 0 \quad \forall k \in\{1,2, \ldots, n\}, \\
& s_{i}^{+} \geq 0 \quad \forall i \in\{1,2, \ldots, s\}, \\
& s_{j}^{-} \geq 0 \quad \forall j \in\{1,2, \ldots, m\},
\end{aligned}
$$

where: $M$ represents the set of input factors; it is the norm or strict positive length or size of the inputs factors. $s_{i}^{+}$and $s_{j}^{-}$are the slack variables associated with output deficits and input excesses respectively. $\mathbf{s}^{+}$and $\mathbf{s}^{-}$vectors comprising $s_{i}^{+}(\forall i \in\{1,2, \ldots, s\})$ and $s_{j}^{-}(\forall j \in\{1,2, \ldots, m\})$. Note above is input oriented that evaluates the optimal weight without constraints on fixed input-output proportions.

The SBM model can be interpreted as the product of input inefficiencies (input excess) and output inefficiencies (output shortfall). In contrast to technical efficiency model which only discriminates between efficient and inefficient DMUs, SBM can further gauge the depth of inefficiency per se. From the SBM model, one can find an optimum input mix which minimized the input excesses of the test companies. Mix efficiency is then defined as the ratio of technical efficiency (TE) and SBM i.e.

$$
(\mathrm{ME})=\theta_{S B M}^{*} / \theta_{V R S}^{*} .
$$

From the managerial perspective, mix efficiency refers to the degree of balances of 
inputs that are used (or outputs that are produced) together.

\subsubsection{Cost efficiency and allocative efficiency model}

In the assessment of productive efficiencies, cost and allocative efficiencies have also gained prominence. Particularly when cost or price data are present, managers are keen to know how to achieve lower costs in production while keeping technical efficiency measure constant. As our data consist of operations costs, we can consider the behavioral objective which is cost minimization. The cost efficiency model is shown below:

$$
\begin{aligned}
\text { (CE) } \min _{\overline{\mathbf{x}}, \lambda} & \theta_{C E}=\sum_{j=1}^{s} \bar{x}_{j o}, \\
\text { s.t. } & \sum_{k=1}^{n} \lambda_{k} y_{i k}-y_{i o} \geq 0 \quad \forall i \in\{1,2, \ldots, s\}, \\
& \sum_{k=1}^{n} \lambda_{k} \bar{x}_{j k}-\bar{x}_{j o} \geq 0 \quad \forall j \in\{1,2, \ldots, m\}, \\
& \lambda_{k} \geq 0 \quad \forall k \in\{1,2, \ldots, n\},
\end{aligned}
$$

where: $\bar{x}_{j o}$ given by $\bar{x}_{j o}=c_{j o} x_{j o}$, is the level of input factor scaled by the factor cost $c_{j o}$ for input factor $j$ of test company o. $\bar{x}_{j k}$ is the level of input factor scaled by the factor cost $c_{j k}$ for input factor $j$ of test company $k$ given by $\bar{x}_{j k o} \quad c_{j k} x_{j k} \cdot \overline{\mathbf{x}}$ is the vector comprising of $\bar{x}_{j o}(\forall j \in\{1,2, \ldots, s\})$.

From the managerial perspective, the cost efficiency model would aim to minimize cost associated with producing a given output. After the obtaining the cost efficiency, one can then calculate the allocative efficiency (AE) by dividing the technical efficiency from the cost efficiency as shown in (Eq. 8) below. The technical efficiency value is obtained from (3) and substituted into (8) as follows.

$$
(\mathrm{AE})=\theta_{C E}^{*} / \theta_{V R S}^{*}
$$

Allocative efficiency measures the ability to minimize costs using inputs in the optimal proportions given their relative prices. For example, if one wants to know how well is the ability of managers in minimizing the cost to achieve technical efficiency, one needs to estimate the allocative efficiency. This measure is essential to gauge the impact of managerial factors on overall firm performance.

\section{Rankings of DMUs}

Traditional DEA models do not allow the analyst to compare the units on the frontier, so it is not possible to fully rank all the samples. From the literature, there are several ways to address this problem i.e., a) using a virtual DMU; b) super efficiency and c) cross efficiency. In super efficiency, a DMU under evaluation is not included in the reference set of the envelopment models (Andersen and Petersen, 1993). This allows possible expansion of all inputs (or contractions of all outputs) for a given unit i.e., how much all inputs can be increased, without being dominated by a linear combination of the other DMUs. The advantage of this method is its simplicity. The disadvantages are: firstly, each value (efficiency score which is used as the rank) is evaluated according to different weights; secondly, this method maybe bias i.e., it may gives "special" DMUs an excessively high rank (Sueyoshi, 1999); and thirdly, the results maybe infeasible if certain pattern of zero data occurs in the inputs and outputs (Zhu, 1996).

In cross efficiency evaluation method, the efficiency score for each DMU is calculated $n$ times, using the weights obtained from the original DEA estimation (Doyle and Green, 1994). The reason of doing this is to ascertain the effect of weights of the other DMUs has on the original DMU's efficiency rating. An average cross efficiency score is then arrived from the re-estimation. Note that the average cross efficiency scores would be lower than the original scores, as a DMU cannot have a cross efficiency score higher than the original 
DEA scores, as this shows each DMU in its best possible light. The advantage of using the cross efficiency method is that it helps eliminate the weighting structure problem in DEA i.e., sometimes most of the weight in a ratio is placed on a single variable, with the rest being given near zero weights. Cross efficiency utilizes the weights of all the units equally; in other words, all the DMUs are evaluated with the same sets of weight vectors. Nevertheless, this is also the drawback of the technique, since the evaluation subsequently loses its connection to the multiplier weights (Adler et al., 2002).

On the other hand, in virtual efficiency, a virtual efficient DMU is introduced and included with the rest of existing DMUs. This will ensure that there is only one efficient DMU with all the other real DMUs being inefficient, in other words, the other real DMUs are penalized for not operating at the same scale of efficiency. This approach serves to rank all the DMUs. According to Bazargan and Vasigh (2003), this ranking is justified because the same virtual DMU is used for all DMUs as the reference set. The advantages of using virtual efficiency are improving discrimination power. Its limitation is it may cause inconsistency as it penalizes all other DMUs for not operating at the same scale efficiency or using similar input proportions and the degrees to which each input factor is penalized may differ.

In this paper, we will use virtual efficiency to obtain a full ranking of the DMUs as this method has been proven its consistency in Martin and Roman (2006). Subsequently, in section 4, we will conduct a statistical comparison of the rankings using virtual efficiency, super efficiency and cross efficiency to provide validity of the results. Results of comparison are attached in Appendix A.

\subsection{Data descriptions}

To assess the efficiency of Iranian real estate and construction companies, we use data for the years 2009 and 2010, obtained from Tehran Stock Exchange. There are altogether 12 companies to be analyzed. According to Golany and Roll (1989), Liu (2005) and Sarkis (2007), the number of DMUs should be at least twice of the total number of input and output factors considered when applying the DEA model.

The first and very crucial step in conducting a DEA analysis is the determination of inputs and outputs. In order to choose the variables, we follow the production procedure whereby the real estate and construction companies are assumed to produce services by performing transactions. Hence, physical inputs (labor and capital) and costs are used as inputs (Zheng et al., 2011). In addition, total assets value is also considered as input because this variable exhibits lower variance and yields more consistent results due to its high correlation with market capitalization. Outputs were chosen to be profit and revenue. These outputs are particularly suitable for analyzing real estates and construction companies' efficiency as they critically depends on managerial decisions (Topuz et al., 2005). The descriptive statistics of input and output factors of the selected real estate and constructions companies are given in Table 1.

\section{EMPIRICAL ANALYSIS}

\subsection{Efficiency results without virtual company}

The detailed DEA efficiency results during the period 2009-2010 are presented in Table 2. (Note: A DEA model is run for each time period analyzed). With the exception of Sar Toosgostar in 2009 (TE $=0.424)$ and Nosazi va Sakhteman in $2010(\mathrm{TE}=0.590)$, however, the efficiency scores of other DMUs are sufficiently close to 1 . This possibly could be due to random errors rather than true inefficiency. For scale efficiencies, all companies register 
a score of near unity in year 2009. However, in 2010, two companies i.e., Sakht Azhand and Sakhteman Isfahan recorded a slight decrease in their scale efficiencies. In general, technical and scale efficiencies among the real estate and construction companies are consistent, the values are above 0.5 except for Sar Toosgostar (=0.424 in 2009). This suggests that the Iranian real estate and construction companies are capable in adjusting their scale of operations with minimal impact on its corresponding production function. Our data showed that in 2009, 50\% of the companies exhibit constant return to scale (CRS), 33.3\% increasing return to scale (IRS) and $16.7 \%$ decreasing return to scale (DRS). In 2010, there is marked increase in the companies' scale expansion, where $42.7 \%$ of the companies are operating at IRS, and $58.3 \%$ operating at CRS. This inferred that the real estate and construction companies are still under the rapidly developing state.

On the other hand, high mix efficiency implies that the company is flexible in changing its input proportions. This is important because input flexibility reduces the company's reliance on specific inputs and cushions it against unexpected shock in demand or price. Sar Toosgostar reports an exceptionally low SBM efficiency in 2009 but subsequently improves and achieves full SBM efficiency in 2010. Similar trend is observed in Sar Maskan. Sakhteman Isfahan's and Sar Samangostar Isfahan's mix efficiency scores are generally acceptable, fluctuating in a narrow range between 0.52 to 0.68 . As for Nosazi va Sakhteman, a sharp increase of approximately $33.3 \%$ in the employment of workers between 2009 and 2010 has led to a fall in its mix efficiency in the subsequent year. All the other companies achieve maximum mix efficiencies throughout the study period.

In terms of cost, Toseh Sakhteman, Sar Azarbayaejan and Shahed are shown to be the only real estate and constructions companies that have achieved full cost efficiency throughout 2009-2010. The other companies are quite lack behind in terms of cost efficiency. The cost effectiveness is not very positive considering the increasing cost for production factor- labor

Table 1. Descriptive statistics for the data

\begin{tabular}{llllllll}
\hline $\begin{array}{l}\text { Year } \\
2009\end{array}$ & Factors & Min & Max & Mean & Std. Dev & Skewness Kurtosis \\
\hline Inputs & $\begin{array}{l}\text { Registered capital (Million } \\
\text { Rials) }\end{array}$ & 54700 & 1090296 & 440352 & 397778.29 & 0.78 & -1.23 \\
& Asset value (Million Rials) & 189936 & 6171082 & 2036746 & 2309473.02 & 0.96 & -0.86 \\
& Operation costs (Million Rials) & 4580 & 1277188 & 354940 & 457124.98 & 1.13 & -0.24 \\
& Employee number (person) & 12 & 175 & 49 & 44.10 & 2.36 & 6.64 \\
Outputs & Revenue (Million Rials) & 8288 & 2525204 & 611073 & 875350.95 & 1.42 & 0.70 \\
& Profit (Million Rials) & -25512 & 1015287 & 210910 & 354387.47 & 1.70 & 1.72 \\
\hline Year & Factors & Min & Max & Mean & Std. Dev & Skewness Kurtosis \\
2010 & & & & & & & \\
\hline Inputs & Registered capital (Million & 54700 & 1500000 & 547438 & 561148.46 & 0.93 & -0.89 \\
& Rials) & & & & & & \\
& Asset value (Million Rials) & 180193 & 6908207 & 2348867 & 2688343.88 & 0.93 & -0.98 \\
& Operation costs (Million Rials) & 11234 & 1379070 & 398785 & 490581.48 & 1.14 & -0.01 \\
& Employee number (person) & 9 & 249 & 56 & 63.57 & 2.93 & 9.42 \\
& Revenue (Million Rials) & 18135 & 1955572 & 606756 & 763910.36 & 1.03 & -0.68 \\
& Profit (Million Rials) & -23507 & 1036906 & 270530 & 379476.61 & 1.08 & -0.38 \\
\hline
\end{tabular}


Table 2. Iranian real estate and construction companies DEA efficiency results without virtual company, 2009-2010

\begin{tabular}{|c|c|c|c|c|c|c|c|c|c|c|c|}
\hline \multirow{3}{*}{$\begin{array}{l}\text { Year } \\
2009\end{array}$} & \multirow{3}{*}{$\begin{array}{l}\text { Company } \\
\text { Abadgaran }\end{array}$} & \multirow{2}{*}{\multicolumn{2}{|c|}{$\begin{array}{l}\text { Technical } \\
\text { efficiency (TE) } \\
\text { q }_{\text {VRS }}\end{array}$}} & \multirow{2}{*}{\multicolumn{2}{|c|}{$\begin{array}{l}\text { Scale } \\
\text { efficiency (SE) } \\
\left(\mathrm{q}_{\mathrm{CCR}} / \mathrm{q}_{\mathrm{VRS}}\right)\end{array}$}} & \multirow{2}{*}{\multicolumn{2}{|c|}{$\begin{array}{l}\text { Mix efficiency } \\
(\mathrm{ME}) \\
\left(\mathrm{q}_{\mathrm{SBM}} / \mathrm{q}_{\mathrm{VRS}}\right)\end{array}$}} & \multirow{2}{*}{\multicolumn{2}{|c|}{$\begin{array}{l}\text { Cost efficiency } \\
\text { (CE) }\end{array}$}} & \multirow{2}{*}{\multicolumn{2}{|c|}{$\begin{array}{l}\text { Allocative } \\
\text { efficiency (AE) } \\
\left(\mathrm{q}_{\mathrm{CE}} / \mathrm{q}_{\mathrm{VRS}}\right)\end{array}$}} \\
\hline & & & & & & & & & & & \\
\hline & & 1.000 & (4) & 1.000 & (4) & 1.000 & (4) & 0.391 & (9) & 0.391 & (10) \\
\hline & $\begin{array}{l}\text { Toseh } \\
\text { Sakhteman }\end{array}$ & 1.000 & (4) & 0.964 & (9) & 1.000 & (4) & 1.000 & (2) & 1.000 & (2) \\
\hline & $\begin{array}{l}\text { Nosazi va } \\
\text { Sakhteman }\end{array}$ & 0.958 & (8) & 0.951 & (10) & 0.730 & (8) & 0.439 & (8) & 0.458 & (8) \\
\hline & Omran Fars & 1.000 & (4) & 1.000 & (4) & 1.000 & (4) & 0.683 & (4) & 0.683 & (6) \\
\hline & Sakht Azhand & 1.000 & $(4)$ & 1.000 & (4) & 1.000 & (4) & 0.547 & (7) & 0.547 & (7) \\
\hline & $\begin{array}{l}\text { Sakhteman } \\
\text { Isfahan }\end{array}$ & 0.779 & (9) & 0.942 & (11) & 0.600 & (11) & 0.342 & (10) & 0.439 & (9) \\
\hline & $\begin{array}{l}\text { Sar } \\
\text { Samangostar } \\
\text { Isfahan }\end{array}$ & 0.744 & (11) & 0.899 & (12) & 0.606 & (10) & 0.640 & (5) & 0.860 & (4) \\
\hline & $\begin{array}{l}\text { Sar } \\
\text { Azarbayaejan }\end{array}$ & 1.000 & (4) & 1.000 & (4) & 1.000 & (4) & 1.000 & (2) & 1.000 & (2) \\
\hline & Sar Toosgostar & 0.424 & (12) & 0.978 & (8) & 0.305 & $(12)$ & 0.143 & (12) & 0.337 & (11) \\
\hline & Sar Maskan & 0.774 & (10) & 1.000 & (4) & 0.626 & (9) & 0.593 & (6) & 0.766 & (5) \\
\hline & Shahed & 1.000 & $(4)$ & 1.000 & (4) & 1.000 & (4) & 1.000 & (2) & 1.000 & (2) \\
\hline & $\begin{array}{l}\text { Sar } \\
\text { Sakhteman }\end{array}$ & 1.000 & (4) & 1.000 & (4) & 1.000 & (4) & 0.233 & (11) & 0.233 & (12) \\
\hline 2010 & Abadgaran & 1.000 & (5) & 1.000 & (4) & 1.000 & (5) & 0.565 & (8) & 0.565 & (9) \\
\hline & $\begin{array}{l}\text { Toseh } \\
\text { Sakhteman }\end{array}$ & 1.000 & (5) & 1.000 & (4) & 1.000 & (5) & 1.000 & $(2.5)$ & 1.000 & (2.5) \\
\hline & $\begin{array}{l}\text { Nosazi va } \\
\text { Sakhteman }\end{array}$ & 0.590 & $(12)$ & 0.808 & (10) & 0.488 & (12) & 0.348 & (11) & 0.590 & (8) \\
\hline & Omran Fars & 1.000 & (5) & 1.000 & (4) & 1.000 & (5) & 0.536 & (10) & 0.536 & (12) \\
\hline & Sakht Azhand & 1.000 & (5) & 0.591 & (12) & 1.000 & (5) & 0.547 & (9) & 0.547 & (10) \\
\hline & $\begin{array}{l}\text { Sakhteman } \\
\text { Isfahan }\end{array}$ & 0.637 & (11) & 0.647 & (11) & 0.518 & (11) & 0.342 & (12) & 0.537 & (11) \\
\hline & $\begin{array}{l}\text { Sar } \\
\text { Samangostar } \\
\text { Isfahan }\end{array}$ & 0.783 & (10) & 0.918 & (9) & 0.675 & (10) & 0.729 & (7) & 0.932 & (5) \\
\hline & $\begin{array}{l}\text { Sar } \\
\text { Azarbayaejan }\end{array}$ & 1.000 & (5) & 0.953 & (8) & 1.000 & (5) & 1.000 & $(2.5)$ & 1.000 & $(2.5)$ \\
\hline & Sar Toosgostar & 1.000 & (5) & 1.000 & (4) & 1.000 & (5) & 0.896 & (5) & 0.896 & (6) \\
\hline & Sar Maskan & 1.000 & (5) & 1.000 & (4) & 1.000 & (5) & 1.000 & $(2.5)$ & 1.000 & $(2.5)$ \\
\hline & Shahed & 1.000 & (5) & 1.000 & (4) & 1.000 & (5) & 1.000 & $(2.5)$ & 1.000 & $(2.5)$ \\
\hline & $\begin{array}{l}\text { Sar } \\
\text { Sakhteman }\end{array}$ & 1.000 & (5) & 1.000 & (4) & 1.000 & (5) & 0.786 & (6) & 0.786 & (7) \\
\hline
\end{tabular}

Note that the ranks are in parentheses. In the event of ties, the median rank is reported. For example, there are 7 DMUs having the same score of 1 , median is 4 . The next following less efficient DMU i.e., the 8th DMU will be given rank 8 and so on, and if there is again a tie, rank 8.5 will be given to the next two DMUs. Median rank is used because it can provide a more uniform or fairer representation for the population. 
and operations. While Sakhteman Isfahan is consistently rated as the low cost efficient (rank 10 in 2009 and 12 in 2010 respectively), of particular concern is company Omran Fars whose ranking in cost efficiency has fallen sharply from $4^{\text {th }}$ position in 2009 to the $10^{\text {th }}$ position in 2010. The low level of cost efficiency of these companies is largely due to the economic and trade sanctions which have been imposed against Iran by numerous nations and multinational entities in recent year in relations to its nuclear program. The sanc- tions have raised the cost of doing business (e.g. increasing the cost of imported industrial goods) for all industries in Iran (Gholipour et al., 2010).

Interestingly, the relationships between the cost, allocative and technical efficiencies can be observed by comparing Figures 2 and 3 . Though cost efficiency is the product of allocative and technical efficiencies, differences in cost efficiencies among the companies seem to be primarily attributable to allocative efficiency. Companies that are more cost efficient

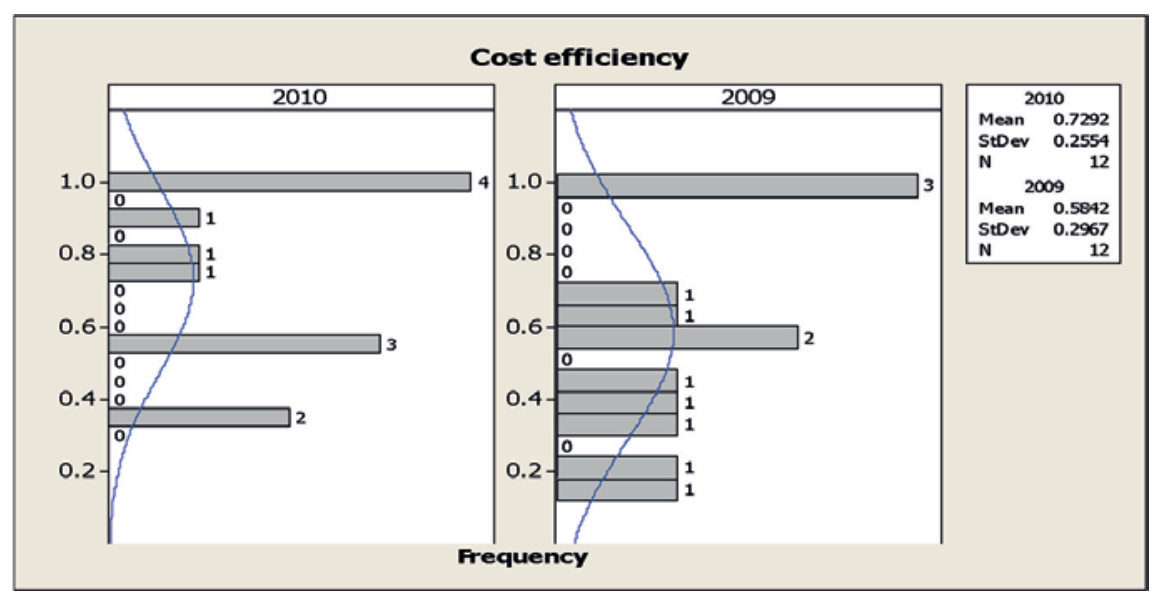

Figure 2. Cost efficiency trend among real estate and construction companies in Iran

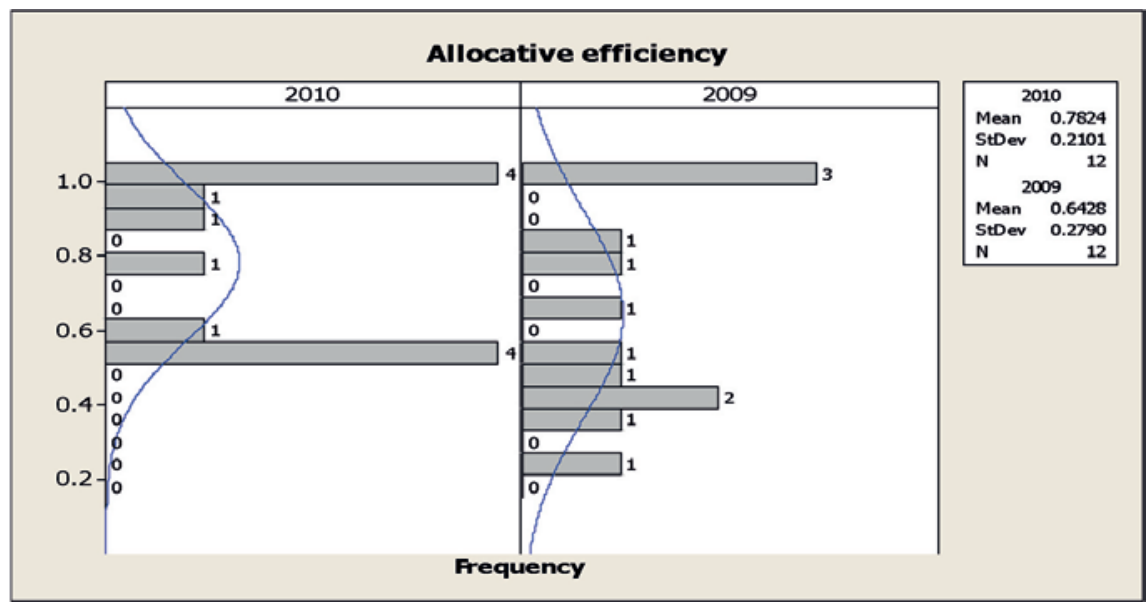

Figure 3. Allocative efficiency among real estate and construction companies in Iran 
are also more allocative efficient concurrently. Though there may be a need for Omran Fars, Sakht Azhand and Sakhteman Isfahan to reverse the fall of their allocative efficiencies from year 2009 to 2010, other companies are either improving or maintaining their ranks of allocative efficiency during the two years. However, there is room for improvement in allocative efficiency among many of the companies to achieve greater cost efficiency.

\subsection{Efficiency results with virtual company}

As can be seen from Table 2, 7 in 12 DMUs are considered efficient, this shows that the original DEA model is lacking of discrimination power. Therefore, to overcome this problem, we use a DEA model with a virtual DMU.

In this paper, we introduce a virtual company following other applications of DEA research (Martin and Roman, 2006), (note that this concept has not been adopted before in any of the real estate and construction literature) the sample set to allow a full ranking of all companies in these efficiency dimensions. Such a virtual company is assumed to be capable of producing the maximum output with the minimum input amongst the set of reference companies. This virtual company, as a superior performer, will always belong to the efficient set that forms the efficient frontier for which the efficiencies of all real companies are evaluated against. Inevitable, the actual computed efficiency scores with the inclusion of the virtual (and perhaps unrealistic) company may not give a fair estimation of the efficiency level. Hence, efficiency results generated with virtual companies are typically used only for relative comparisons (or rankings) amongst the set of reference companies. Note that it is clear that without using virtual company, it precludes DMUs from a full ranking. Appendix A provided the statistical evidence on the validity of the results obtained using virtual company and the results showed that the virtual method is robust and valid.

From Table 3, Sakht Azhand, Sar Azarbayaejan and Omran Fars are three companies that constantly perform equally well as the virtual company in terms of technical efficiency. Note that their rankings maintained at the top three level in the two years study period. While Abadgaran climbed from $6^{\text {th }}$ position in 2009 to the $5^{\text {th }}$ position in 2010 , and Sar Samangostar Isfahan improved from $9^{\text {th }}$ position to $8^{\text {th }}$ position in 2010 , the rankings of other companies on technical efficiency appear to be rather stable. Nosazi va Sakhteman and Sar Toosgostar are moderate performers in almost every year of the study horizon. Shahed, Sar Maskan and Toseh Sakhteman take the last three positions.

In terms of scale efficiency, Sakht Azhand and Sakhteman Isfahan are amongst the lowest ranked companies owing to their large investments in capacity (e.g., labor). When demand falls, the large workforce cannot be contracted at short notice and wasteful underutilization may occur. Meanwhile, companies such as Shahed, Sar Maskan, Sar Sakhteman and Toseh Sakhteman are seen to be most scale efficient. This set of scale efficient companies however are not mix efficient, indicating that difficulties in the ability to change the proportions of their input usages may occur. Sar Samangostar is a moderate performer but Omran Fars's performance is deteriorating. Nonetheless, the rankings between Nosazi va Sakhteman and Sar Toosgostar are somewhat volatile across years.

In terms of cost efficiency, Sar Azarbayaejan is the second highest ranked company in two consecutive years 2009 and 2010. This indicates that the company managed to keep its cost of production (e.g., labor and operations costs) low amidst of fluctuation of prices. This result is also consistent with the results obtained from the original model. Interestingly, 
Table 3. Iranian real estate and construction companies DEA efficiency results with virtual company, 2009-2010

\begin{tabular}{|c|c|c|c|c|c|c|c|c|c|c|c|}
\hline \multirow{2}{*}{$\begin{array}{l}\text { Year } \\
2009\end{array}$} & \multirow{2}{*}{$\begin{array}{l}\text { Company } \\
\text { Abadgaran }\end{array}$} & \multicolumn{2}{|c|}{$\begin{array}{l}\text { Technical } \\
\text { efficiency (TE) } \\
q_{\text {VRS }}\end{array}$} & \multicolumn{2}{|c|}{$\begin{array}{l}\text { Scale } \\
\text { efficiency (SE) } \\
\left(\mathrm{q}_{\mathrm{CCR}} / \mathrm{q}_{\mathrm{VRS}}\right) \\
\end{array}$} & \multicolumn{2}{|c|}{$\begin{array}{l}\text { Mix efficiency } \\
(\mathrm{ME}) \\
\left(\mathrm{q}_{\mathrm{SBM}} / \mathrm{q}_{\mathrm{VRS}}\right)\end{array}$} & \multicolumn{2}{|c|}{$\begin{array}{l}\text { Cost efficiency } \\
\text { (CE) }\end{array}$} & \multicolumn{2}{|c|}{$\begin{array}{l}\text { Allocative } \\
\text { efficiency (AE) } \\
\left(\mathrm{q}_{\mathrm{CE}} / \mathrm{q}_{\mathrm{VRS}}\right)\end{array}$} \\
\hline & & 0.654 & (6) & 0.058 & (9) & 0.443 & (4) & 0.353 & (5) & 0.540 & (9) \\
\hline & $\begin{array}{l}\text { Toseh } \\
\text { Sakhteman }\end{array}$ & 0.057 & (13) & 1.000 & (2) & 0.037 & (13) & 0.053 & $(12.5)$ & 0.928 & (4) \\
\hline & $\begin{array}{l}\text { Nosazi va } \\
\text { Sakhteman }\end{array}$ & 0.370 & (8) & 0.142 & (6) & 0.174 & (8) & 0.177 & (8) & 0.477 & (10) \\
\hline & Omran Fars & 0.737 & (4) & 0.071 & (8) & 0.429 & (5) & 0.520 & (4) & 0.705 & (5) \\
\hline & Sakht Azhand & 0.945 & (3) & 0.032 & $(12)$ & 0.795 & (2) & 0.530 & (3) & 0.561 & (8) \\
\hline & $\begin{array}{l}\text { Sakhteman } \\
\text { Isfahan }\end{array}$ & 0.506 & (7) & 0.044 & (11) & 0.280 & (6) & 0.331 & (6) & 0.655 & (6) \\
\hline & $\begin{array}{l}\text { Sar } \\
\text { Samangostar } \\
\text { Isfahan }\end{array}$ & 0.239 & (9) & 0.123 & (7) & 0.163 & (10) & 0.239 & (7) & 1.000 & $(2.5)$ \\
\hline & $\begin{array}{l}\text { Sar } \\
\text { Azarbayaejan }\end{array}$ & 0.969 & (2) & 0.054 & $(10)$ & 0.645 & (3) & 0.969 & (2) & 1.000 & $(2.5)$ \\
\hline & Sar Toosgostar & 0.213 & (10) & 0.024 & (13) & 0.167 & (9) & 0.138 & (9) & 0.649 & (7) \\
\hline & Sar Maskan & 0.137 & (12) & 0.613 & (4) & 0.057 & (12) & 0.053 & (12.5) & 0.387 & (12) \\
\hline & Shahed & 0.185 & (11) & 0.821 & (3) & 0.080 & (11) & 0.073 & (10) & 0.397 & (11) \\
\hline & $\begin{array}{l}\text { Sar } \\
\text { Sakhteman }\end{array}$ & 0.667 & (5) & 0.245 & (5) & 0.188 & (7) & 0.049 & (11) & 0.073 & (13) \\
\hline \multirow[t]{12}{*}{2010} & Abadgaran & 0.637 & (5) & 0.055 & (9) & 0.441 & (6) & 0.333 & (6) & 0.523 & (10) \\
\hline & $\begin{array}{l}\text { Toseh } \\
\text { Sakhteman }\end{array}$ & 0.033 & (13) & 0.964 & (4) & 0.027 & (13) & 0.033 & (12.5) & 1.000 & (2) \\
\hline & $\begin{array}{l}\text { Nosazi va } \\
\text { Sakhteman }\end{array}$ & 0.222 & (9) & 0.069 & (8) & 0.144 & (9) & 0.167 & (9) & 0.750 & (6) \\
\hline & Omran Fars & 0.890 & (4) & 0.030 & (11) & 0.559 & (5) & 0.490 & (5) & 0.551 & (9) \\
\hline & Sakht Azhand & 0.999 & (2) & 0.010 & (13) & 0.796 & (3) & 0.500 & (4) & 0.501 & (11) \\
\hline & $\begin{array}{l}\text { Sakhteman } \\
\text { Isfahan }\end{array}$ & 0.505 & (6) & 0.016 & $(12)$ & 0.331 & (7) & 0.312 & (7) & 0.619 & (8) \\
\hline & $\begin{array}{l}\text { Sar } \\
\text { Samangostar } \\
\text { Isfahan }\end{array}$ & 0.225 & (8) & 0.113 & (7) & 0.158 & (8) & 0.225 & (8) & 1.000 & (2) \\
\hline & $\begin{array}{l}\text { Sar } \\
\text { Azarbayaejan }\end{array}$ & 0.960 & (3) & 0.032 & (10) & 0.649 & (4) & 0.914 & (2) & 0.952 & (4) \\
\hline & Sar Toosgostar & 0.195 & (10) & 0.262 & (6) & 0.131 & (10) & 0.130 & (10) & 0.668 & (7) \\
\hline & Sar Maskan & 0.118 & $(12)$ & 0.998 & (3) & 0.047 & $(12)$ & 0.033 & (12.5) & 0.283 & $(12)$ \\
\hline & Shahed & 0.157 & (11) & 0.806 & (5) & 0.066 & (11) & 0.050 & (11) & 0.317 & (13) \\
\hline & $\begin{array}{l}\text { Sar } \\
\text { Sakhteman }\end{array}$ & 0.471 & (7) & 1.000 & $(2)$ & 1.000 & (2) & 0.786 & (3) & 0.786 & (5) \\
\hline
\end{tabular}


a wide contrast in the efficiencies of Toseh Sakhteman and Shahed were observed using the model with virtual company. The original model showed that both companies were fully efficient in terms of cost efficiency as well scale efficiency in year 2009 and 2010. The outputs from the virtual model however, indicated, cost efficiency and scale efficiency of both companies do not necessarily behave well together. For instance, Toseh Sakhteman in year 2009 was ranked $2^{\text {nd }}$ in terms of scale efficiency, but was ranked $12^{\text {th }}$ in terms of cost efficiency. Similarly, Shahed was ranked $5^{\text {th }}$ in terms of scale efficiency in year 2010, but was ranked $11^{\text {th }}$ for cost efficiency. The higher discrimination power of the virtual model does not only able to provide a full ranking for all companies in these efficiencies dimensions, but also able to provide additional insight that cost efficiency will somewhat offset scale efficiency. It seems that increases in scale of operation may allow exploitation of gains from cost efficiency for some firms. This has implications for the companies' restructuring exercise; for example, the merger of the firms will result in increasing competitiveness of the real estates and construction companies in Iran.

In terms of allocative efficiency, Sar Azarbayaejan, Sar Samangostar and Toseh Sakhteman are among the highest ranked companies in year 2009 and 2010. The results are consistent with the outputs produced by the original model. However, in contrast to the original model, the higher discrimination power of the virtual model is able to provide a contrasting behaviour of Toseh Sakheman for its cost and allocative efficiencies. It signified that cost and allocative efficiencies may not necessarily behave in a similar way for all firms. Note that though Toseh Sakhteman was ranked $12^{\text {th }}$ in terms of cost efficiency in year 2009 , it was ranked $4^{\text {th }}$ in terms of allocative efficiency in the same year. Similarly, in year 2010 , it had a rank of $13^{\text {th }}$ in terms of cost efficiency, but was ranked $2^{\text {nd }}$ for allocative efficiency. The results indicated that in some circumstances, offset between cost and allocative efficiency may happen. For instances, fluctuation in prices increases cost of operations, hence, this made the company perform badly in terms of cost efficiency. However, if the management is capable to make long term decisions to compensate for cost, e.g., the management takes drastic actions to reduce idle capacity and staff redundancies, thus this would lead to high allocative efficiency in the company.

\section{DISCUSSION}

The importance of technical efficiency to the real estates and construction companies cannot be understated owing to its implications on scale and mix efficiencies. From the DEA models presented in prior sections, we see that scale efficiency is defined as the ratio of CCR and VRS, whereas mix efficiency is the ratio of SBM and VRS efficiencies. Since SBM is always less than or equal to VRS, a real estate and construction company needs to be technically efficiency to achieve full scale efficiency. The attainment of full technical efficiency is bounded by many other considerations. For example, an expansion in the intangible resources (e.g. labor) is indivisible. As it is not quite possible to fit the capacity (workforce) of the company exactly to the expected demand, companies operating under congestions (constraints) may appear to be more efficient. Second, there is a time lag between the initial investments in resources e.g., workers need to undergo training before they are ready to contribute to service. Hence, the organization will need to implement its training in advance even though the early recruitment causes inefficiency in the short term due to underutilization.

Of particular interest is the cost efficiency of the real estates and construction companies. Putting service issues aside, cost efficiency 
determines the competitiveness of the company to a large extent. There appears to be a 'resource or human specific' effect in that companies having more labors are less cost efficient compared to those having less labor. The degree of allocative efficiency among these companies is also quite similar considerably. The significant connection between cost efficiency and allocative efficiency highlights that the softer aspect such as good managerial judgment make a significant difference to the overall cost competitiveness of the real estate and construction companies.

Finally, some disparities were observed between the rankings assigned to the companies with and without the virtual company. Though, there are some drawbacks that cause the inconsistency in ranking results, e.g., the assumption that all other companies are operating at different input proportions and different degree of penalization in each input factor. Despite these drawbacks, the ranking based on the assumption of the existence of an efficient virtual company has been justified in previous studies (Martin and Roman, 2006).

\section{SENSITIVITY ANALYSIS AND MANAGERIAL IMPLICATIONS}

As the technique of DEA is non-parametric and does not provide statistical means of the results, a sensitivity test using window analysis (Charnes et al., 1985) is undertaken. Window analysis allows for an assessment of the stability of relative efficiency scores over time by using a moving average analogue where a DMU in each different period is treated as if it was a 'different' DMU. Here, we consider a window length of one year and the results of the mean of each DMU are tabulated in Figure 4 for comparison. We used a radar chart to present the results for clearer and better illustration of the stability.

Following Charnes et al. (1985) recommendations, the efficiency scores from model (3) were chosen to run the window analysis. (Note that this is also to eliminate random noise factors in the efficiency score). The mean of the efficiency scores over the time period of 2009 2010 are Abadgaran (1.000), Toseh Sakhteman (1.000), Nosazi va Sakhteman (0.774),

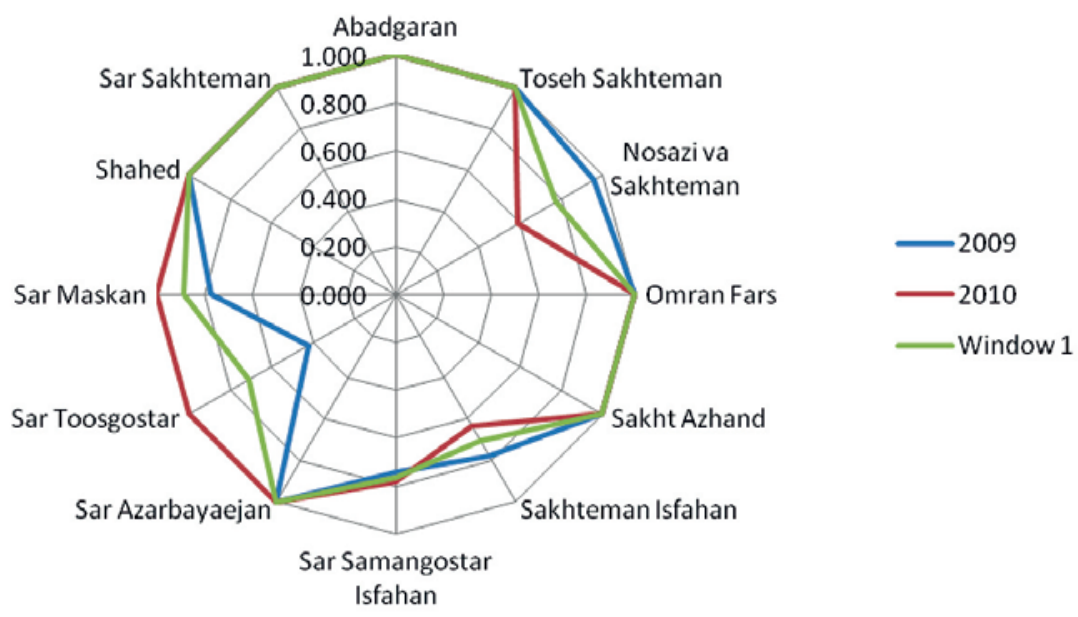

Figure 4. Stability of relative efficiency scores using Window Analysis 
Omran Fars (1.000), Sakht Azhand (1.000), Sakhteman Isfahan (0.708), Sar Samangostar Isfahan (0.764), Sar Azarbayaejan (1.000), Sar Toosgostar (0.712), Sar Maskan (0.887), Shahed (1.000) and Sar Sakhteman (1.000) respectively. Though there are some ripples in the efficiency scores for Sar Toosgostar, Sar Maskan and Nosazi va Sakhteman over the time period, it can be seen that there is a fair amount of stability in the efficiency scores for all the other DMUs. Thus, the above evidence of stability in the industry growth lends credibility to the implications drawn from the DEA results.

Next, we further conduct sensitivity analysis on each type of efficiencies. To do so, we need to calculate the changes in the efficiency using this formula: change $=(($ efficiency values in 2010 - efficiency values in 2009) / efficiency values in 2009)) $\times 100 \%$.

Positive percentage values indicate that there is an improvement in the respective category of efficiency. From Table 4, it was observed that among the significant improvements were Sar Toogostar (in all types of efficiencies) and Sar Sakhteman (in cost and allocative efficiencies). Taking on the overall efficiency changes, which is calculated based on the average of all types of efficiencies, all the companies recorded a marked improvement in the overall efficiency except for Nosazi va Sakhteman, Omran Fars and Sakhteman Isfahan. A common factor that pulled down the efficiency of these three companies is the negative changes encountered in scale efficiency. In addition, on the average, all types of efficiencies improve from the previous years (see Table 4), except for scale efficiency. Scale efficiency recorded a change of $-6.99 \%$ in comparison with the previous year performance. Mix efficiency recorded a change of $21.02 \%$, cost efficiency $70.73 \%$ and followed by allocative efficiency $43.02 \%$ in comparison to previous year's performance. This indicates that while managerial efficiency in managing operations, input mix, cost and allocation of resources had improved, however, economies of scales has not been improving. Also, as cost efficiency is decomposed into technical and allocative efficiency, high level of improvement in cost efficiency from year 2009 to 2010 is mainly due to allocative efficiency. Average technical efficiency is $\sim 9 \%$, this implies that many firms in Iran failed to attain optimal cost-minimizing input mix during the year 2009-2010.

Table 4. Sensitivity analysis on efficiencies for each company

\begin{tabular}{lllllll}
\hline Company & $\begin{array}{l}\text { Technical } \\
\text { change (\%) }\end{array}$ & $\begin{array}{l}\text { Scale } \\
\text { change (\%) }\end{array}$ & $\begin{array}{l}\text { Mix } \\
\text { change (\%) }\end{array}$ & $\begin{array}{l}\text { Cost } \\
\text { change (\%) }\end{array}$ & $\begin{array}{l}\text { Allocative } \\
\text { change (\%) }\end{array}$ & $\begin{array}{l}\text { Average } \\
\text { overall } \\
\text { efficiency }\end{array}$ \\
\hline Abadgaran & 0.00 & 0.00 & 0.00 & 44.50 & 44.50 & 7.30 \\
Toseh Sakhteman & 0.00 & 3.73 & 0.00 & 0.00 & 0.00 & 0.90 \\
Nosazi va Sakhteman & -38.41 & -15.04 & -33.15 & -20.73 & 28.82 & -5.67 \\
Omran Fars & 0.00 & 0.00 & 0.00 & -21.52 & -21.52 & -2.82 \\
Sakht Azhand & 0.00 & -40.90 & 0.00 & 0.00 & 0.00 & -2.70 \\
Sakhteman Isfahan & -18.23 & -31.32 & -13.67 & 0.00 & 22.32 & -2.81 \\
Sar Samangostar & 5.24 & 2.11 & 11.39 & 13.91 & 8.37 & 3.64 \\
Isfahan & & & & & 0.00 & 0.25 \\
Sar Azarbayaejan & 0.00 & -4.70 & 0.00 & 526.57 & 165.88 & 81.84 \\
Sar Toosgostar & 135.85 & 2.25 & 227.87 & 68.63 & 30.55 & 15.01 \\
Sar Maskan & 29.20 & 0.00 & 59.74 & 0.00 & 0.00 & 0.62 \\
Shahed & 0.00 & 0.00 & 0.00 & 0.00 & 36.98 \\
Sar Sakhteman & 0.00 & 0.00 & 0.00 & 237.34 & 237.34 & - \\
\hline Average changes & 9.47 & -6.99 & 21.02 & 70.73 & 43.02 & \\
\hline
\end{tabular}


The findings above provided several important insights to managers and potential investors. From the economical context, the results showed that most of the real estate and construction companies are experiencing diseconomies of scale (from the decreasing results in scale efficiency). The decrease of $6.99 \%$ in scale efficiency indicated that the companies are not optimizing their performance with respect to their size of operations. As can be seen from the technical efficiency, most companies are performing well and there is a positive improvement of $+9.47 \%$ from year 2009 to 2010 . However, the change is not significantly strong enough to commensurate the growing market. Firms need to increase their market power to allow a higher growth in the real estates and construction market. From the technical point of view, note that scale efficiency is related to technical efficiency; if technical efficiency increases, scale efficiency will be inversely affected; hence, to achieve a positive growth effect in parallel to improvement in operational efficiency, firms need to increase their market power by increasing their size of operation. One way to achieve this is through merger and acquisition. Hence, potential investors could tap into this opportunity by forming merger and acquisition to help the company achieve the much needed economies of scale.

While the positive overall change in cost efficiency and allocative efficiency (of $70.73 \%$ and $43.02 \%$ respectively) had indicated that from the operational context (recall that we have discussed this in detail in section 5), most companies have a good management team reacting to the changing market conditions, several insights as well can be inferred from the financial context. As financial context are more into areas of cost, return and risk, we will discuss it from the perspective of cost efficiency. Of particular concerns are the companies which recorded a negative percentage change in cost efficiency i.e., Nosazi va Sakhteman and Om- ran Fars. These two companies need further concentration to enhance their cost efficiencies. For example, instead of covering such a wide scope of real estate and construction market like residential, retail, industrial and office buildings, they should limit down their focus on only a few selected areas, i.e., their niche areas. By doing so, they can lower their operating expenses and limit their debts, and subsequently with a lower proportion of debt it can help to improve their cost efficiency. In addition, these two companies as well as the other companies which are performing well in cost efficiency should not neglect their capital risk. Capital soundness though may act as their efficiency stimulant, but, it may also pose great danger as it will encourage manager to pursue riskier projects and be less attentive to efficiency.

The results of efficiency performance of the real estate and construction companies in Iran not only have provided invaluable insights to the managers of the companies (e.g., tell them what action and strategy to take to further improve performance), the results had also benefitted potential investors, policy makers and stakeholders. For the potential investors, through the results, they had actually gained added advantages by knowing the actual performance of the companies prior to business engagement. For the policy makers, the results can guide them how they can help the companies to improve performance, e.g., to help the company achieve economy of scale, they can remove restrictions, control prices, or exert timely nudging through policy intervention. For the stakeholders of the real estate market in Iran, through the efficiency results, one is able to gauge the actual performance of the companies in Iran; with this, it helps to stamp out excessive speculative buying and keep the market tied or running not too far from underlying fundamentals. 


\section{CONCLUSIONS}

This paper contributes to the existing real estate and construction literature by presenting a comprehensive assessment of efficiencies of major companies in Iran using the DEA technique. It shows how do the real estate and construction companies in Iran perform in various efficiency aspects. The results indicate that it is rather difficult for one company to be both technical and cost efficient. Nevertheless, this may not be impossible to achieve if the company knows its sources of inefficiencies and implements measures to improve the inefficient areas.

While the DEA application to real estate efficiency context may not be new, past researches had primarily focused within the internal operational analysis and in developed markets. In contrast, our study had discriminated against various efficiency sources which further connote the overall cost competitiveness of the organizations and also focus on underdeveloped market, i.e., Iran which is a huge potential market for investors. Results from our analysis reveal that most of the real estate and construction companies in Iran are generally technical, scale and mix efficient. However, they are less cost efficient due to macro-economy effect such as higher cost of production factors and lower allocative efficiency. Sensitivity analysis results indicated that the companies are experiencing diseconomies of scale, this signifies business opportunities for potential investors for forming mergers and acquisitions to achieve cost economies. The efficiency results also help to guide investors, government and policy makers to accurately gauge the performance of the companies, further alienating excessive speculation in real estate markets.

Future research study can include methodological enhancement on the capabilities of existing DEA models to measure the long-run efficiency which takes into account the time lag of capital investment and include observations with fuzzy and missing data. In addition, we may also construct a stochastic frontier with a disturbance term representing shifts in the frontier due to random factors and compare the results obtained against those of a deterministic frontier.

\section{ACKNOWLEDGEMENTS}

This study was supported by the research grant from Research Creativity and Management Office of Universiti Sains Malaysia (Account No: 1001/PMGT/844090).

\section{REFERENCES}

Abdul-Rasheed, A. and Tajudeen, A. B. (2006) Performance analysis of listed construction and real estate companies in Nigeria, Journal of Real Estate Portfolio Management, 17(2), pp. 177-185.

Adler, N., Friedman, L. and Sinuany-Stern, Z. (2002) Review of ranking methods in the data envelopment analysis context, European Journal of Operational Research, 140(2), pp. 249-265. http://dx.doi.org/10.1016/S03772217(02)00068-1

Ali, A. I. and Seiford, L. M. (1993) The mathematical programming approach to efficiency analysis. In: Fried, H. O., Lovell, C. A. K. and Schmidt, S. S. (Eds.), The measurement of productive efficiency, Oxford University Press, New York, pp. 120-159.

Andersen, P. and Petersen, N. C. (1993) A procedure for ranking efficient units in data envelopment analysis, Management Science, 39(10), pp. 1261-1264.

http://dx.doi.org/10.1287/mnsc.39.10.1261

Anderson, R. I., Fok, R., Springer, T. and Webb, J. (2002) Technical efficiency and economies of scale: A non-parametric analysis of REIT operating efficiency, European Journal of Operational Research, 139(3), pp. 598-612. http:// dx.doi.org/10.1016/S0377-2217(01)00183-7

Bazargan M. and Vasigh, B. (2003) Size versus efficiency: A case study of US commercial airports, Journal of Air Transportation Management, 9(3), pp. 187-193. http://dx.doi.org/10.1016/ S0969-6997(02)00084-4 
Bers, M. and Springer, T. M. (1997) Economies-ofscale for real estate investment trusts, Journal of Real Estate Research, 14(3), pp. 275-290.

Charnes, A., Cooper, W. W. and Rhodes, E. (1978) Measuring the efficiency of decision making units, European Journal of Operation Research, 2(6), pp. 429-444. http://dx.doi. org/10.1016/0377-2217(78)90138-8

Charnes, A., Clark, C. T., Cooper, W. W., and Golany, B. (1985) A developmental study of data envelopment analysis in measuring the efficiency of maintenance units in the US Air Forces, $A n$ nals of Operations Research, 2(1), pp. 95-112. http://dx.doi.org/10.1007/BF01874734

Cummins, J. D., Weiss, M. A., Xie, X. and Zi, H. (2010) Economies of scope in financial services: A DEA efficiency analysis of the US insurance industry, Journal of Banking \& Finance, 34(7), pp. 1525-1539. http://dx.doi.org/10.1016/j. jbankfin.2010.02.025

Cummins, J. D. and Zi, H. (1998) Comparison of frontier efficiency methods: An application to the U.S. life insurance industry, Journal of Productivity Analysis, 10(2), pp. 131-152. http://dx.doi.org/10.1023/A:1026402922367

Doyle, J. R. and Green, R. (1994) Efficiency and cross-efficiency in DEA: derivations, meanings and uses, Journal of the Operational Research Society, 45(5), pp. 567-578.

http://dx.doi.org/10.1057/jors.1994.84

El-Mashaleh, M. S., Minchin, R. E. and O’Brien, W. J. (2007) Management of construction firm performance using benchmarking, Journal of Management in Engineering, 23(1), pp. 10-17. http://dx.doi.org/10.1061/(ASCE)0742597X(2007)23:1(10)

Farrell, M. J. (1957) The measurement of productive efficiency, Journal of the Royal Statistical Society. Series A, 120(3), pp. 253-290.

Gholipour, H. F., Tajul, A. M., Nikbin, D. and Ekhtiari, R. A. (2010) Consequences of external environment on entrepreneurial motivation in Iran, Asian Academy of Management Journal, 15(2), pp. 175-196.

GMID (2011) Global market information databases. [Online] Available at: http://www.portal. euromonitor.com/Portal/Pages/Magazine/WelcomePage.aspx [accessed 5 July 2011]

Golany, B. and Roll, Y. (1989) An application procedure for DEA, Omega-International Journal of Management Science, 17(3), pp. 237-250. http://dx.doi.org/10.1016/0305-0483(89)90029-7
Hollingsworth, B. (2008) The measurement of efficiency and productivity of health care delivery, Health Economics, 17(10), pp. 1107-1128. http://dx.doi.org/10.1002/hec.1391

Horta, I. M., Camanho, A. S. and Costa, J. M. (2011) Assessment of performance and innovation of Portuguese construction companies. In: 15 Congresso da Associacao Portuguesa de Investigacao Operacional, 18-20 April 2011, University of Coimbra, pp. 115-127.

Hui, E. C. M., Ooi, J. T. L. and Wong, K. (2007) Economic performance of property companies in Hong Kong, Journal of Property Research, 24(2), pp. 139-157. http://dx.doi. org/10.1080/09599910701440123

Liu, C. (2005) Measuring the relative efficiency and reorganization - The example of CDFAs of the NAN-TOU County in Taiwan, Economics Bulletin, 17(9), pp. 1-11.

Martin, J. C. and Roman, C. (2006) A benchmarking analysis of Spanish commercial airports. A comparison between SMOP and DEA ranking methods, Networks and Spatial Economics, 6(2), pp. 111-134. http://dx.doi.org/10.1007/ s11067-006-7696-1

Miller, S. M., Clauretie, T. M. and Springer, T. M. (2006) Economies of scale and cost efficiencies: A panel-data stochastic-frontier analysis of real estate investment trusts, Manchester School, 74(4), pp. 483-499. http://dx.doi.org/10.1111/ j.1467-9957.2006.00505.x

Miller, S. M. and Springer, T. M. (2007) Cost improvements, returns to scale, and cost inefficiencies for real estate investment trusts, University of Connecticut, Department of Economics Working Papers Series, Working Paper 2007-05.

Odeck, J. (2008) The effect of mergers on efficiency and productivity of public transport services, Transportation Research Part A: Policy and Practice, 42(4), pp. 696-708. http://dx.doi. org/10.1016/j.tra.2007.12.004

Ozcan, Y. A. (2008) Health care benchmarking and performance evaluation: An assessment using Data Envelopment Analysis (DEA), International Series in Operations Research and Management Science, Vol. 120, Springer, New York.

Pan, Y. and Yang, L. (2010) Economies of scale in Chinese real estate industry: A translog cost function based analysis. In: Second International Conference on Communication Systems, 
Networks and Applications, 29 June-1 July 2010, Hong Kong, Vol. 2, pp. 337-340.

Sarkis, J. (2007) Preparing your data for DEA. In: Zhu, J. and Cook, W. D. (eds.), Modeling data irregularities \& structural complexities in data, Springer, pp. 305-320.

Seol, H., Lee., H., Kim, S. and Park, Y. (2008) The impact of information technology on organizational efficiency in public services: A DEAbased DT approach, Journal of the Operational Research Society, 59(2), pp. 231-238. http:// dx.doi.org/10.1057/palgrave.jors.2602453

Shi, G., Bi, J. and Wang, J. (2010) Chinese regional industrial energy efficiency evaluation based on a DEA model of fixing non-energy inputs, Energy Policy, 38(10), pp. 6172-6279. http://dx.doi.org/10.1016/j.enpol.2010.06.003

Siriopoulos, C. and Tziogkidis, P. (2010) How do Greek banking institutions react after significant events? A DEA approach, Omega-International Journal of Management Science, 38(5), pp. 294-308.

http://dx.doi.org/10.1016/j.omega.2009.06.001

Sueyoshi, T. (1999) DEA non-parametric ranking test and index measurement: slack-adjusted DEA and an application to Japanese agriculture cooperatives, Omega-International Journal of Management Science, 27(3), pp. 315-326. http:// dx.doi.org/10.1016/S0305-0483(98)00057-7

Tone, K. (2001) A slacks-based measure of efficiency in data envelopment analysis, European Journal of Operational Research, 130(3), pp. 498-509. http://dx.doi.org/10.1016/S03772217(99)00407-5

Topuz, J. C., Darrat, A. F. and Shelor, R. M. (2005) Technical, allocative and scale efficiencies of REITs: An empirical inquiry, Journal of Business Finance \& Accounting, 32(9-10), pp. 1961-1994. http://dx.doi.org/10.1111/j.0306686X.2005.00653.x
Tsolas, I. E. (2011) Modelling profitability and effectiveness of Greek-listed construction firms: An integrated DEA and ratio analysis, Construction Management and Economics, 29(8), pp. 795-807. http://dx.doi.org/10.1080/01446193. 2011.610330

Wang, T. and Wang, G. (2009) Empirical analysis of operating efficiency of China's real estate industry, Science Technology and Industry, 9(10), pp. 39-43.

Wang, Y. S. and Chau, K. W. (2001) An assessment of the technical efficiency of construction firms in Hong Kong, International Journal of Construction Management, 1(1), pp. 21-29.

Wu, J., Liang, L. and Yang, F. (2009) Achievement and benchmarking of countries at the Summer Olympics using cross efficiency evaluation method, European Journal of Operational Research, 197(2), pp. 722-730. http://dx.doi.org/10.1016/j.ejor.2008.06.030

Yang, H., Yeung, J. F. Y., Chan, A. P. C., Chiang, Y. H. and Chan, D. W. M. (2010) A critical review of performance measurement in construction, Journal of Facilities Management, 8(4), pp. 269-284.

http://dx.doi.org/10.1108/14725961011078981

You, T. and Zi, H. (2007) The economic crisis and efficiency change: evidence from the Korean construction industry, Applied Economics, 39(14), pp. $1833-1842$.

http://dx.doi.org/10.1080/00036840600690199

Zheng, X., Chau, K. W. and Hui, E. C. M. (2011) Efficiency assessment of listed real estate companies: An empirical study of China, International Journal of Strategic Property Management, 15(2), 91-104. http://dx.doi.org/10.3846/164871 5X.2011.582739

Zhu, J. (1996) Robustness of the efficient DMUs in data envelopment analysis, European Journal of Operational Research, 90(3), pp. 451-460. http://dx.doi.org/10.1016/0377-2217(95)00054-2 


\section{APPENDIX A}

According to Martin and Roman (2006), no one methodology can be prescribed as the best option to fully rank DMU and each method may be useful in explaining the overall performance. Our focus in this paper is to extract practical lessons that may be used by managers or regulators in order to obtain the best option to fully rank the DMUs. Hence, virtual efficiency is chosen based on three advantages/ reasons: 1) one gets full rank; b) ranking obtained with this method has been consistent; c) results are more robust. Note that b) and c) has been justified by Martin and Roman (2006) and the authors had further iterated that the virtual efficiency technique can be applied in future without apology. In this paper, we investigated the validity of the results by finding the correlation between virtual efficiency and other full ranking methods. Table A.1 shows the Pearson correlations statistics of the scores between different techniques of full ranking i.e., cross efficiency, super efficiency, virtual efficiency and the traditional DEA model.

On the basis of comparison with the traditional model, note that the $p$-value shows that there is a statistical difference between the cross efficiency and super efficiency with the traditional model. This means that the average values of efficiency scores are not the same for both techniques compared to the traditional way; the null hypotheses i.e. $H_{0}: \mathrm{m}_{1}=\mathrm{m}_{2}$ has to be rejected at level of significance $a=0.001$ and $a=0.05$ for cross and super efficiency respectively. In contrast, the $p$-value of virtual efficiency $(=0.141)$ showed that the null hypothesis is accepted, which means there is no significant difference between the averages of the virtual efficiency with the traditional way. Another interesting point to highlight also is that, the statistical validity of virtual efficiency is maintained whereby, the $p$-value of $(=0.486)$ and $(=0.719)$ with cross efficiency and super efficiency, indicated that the averages scores between these techniques are equivalent. This signifies that the results produced by the virtual efficiency technique are quite stable and robust. Overall, the results show that there is a relationship between virtual efficiency and the traditional model. Hence, the results obtained through the virtual method can be considered robust and valid.

Table A.1. Pearson correlation statistics of ranking methods

\begin{tabular}{llll}
\hline & Cross efficiency & Super efficiency & Virtual efficiency \\
\hline Super efficiency & 0.004 & & \\
Virtual efficiency & 0.486 & 0.719 & \\
Traditional & 0.000 & 0.021 & 0.141 \\
\hline
\end{tabular}

